\title{
A Cascade PI-SMC Method for Brushless Doubly-Fed Induction Machine with Matrix Converter
}

Hui Wang, Xun Zhao, Hanbing Dan, Mei Su, Yao Sun, Zhengzhang Di, Mpio Mviri Franck Soleil, Marco

Rivera, Patrick wheeler

\begin{abstract}
This paper proposes a cascade proportional-integral continuous second-order sliding mode control method for brushless doubly-fed induction machine. This method consisting of speed out-loop Proportional-Integral controller and current inner-loop sliding mode controller. The PI controller provides reference to the inner-loop sliding mode controller with constraints according to the system requirements in terms of maximum current and speed limits. The sliding mode control method is designed to achieve excellent robustness and anti-interference ability, which is suitable for machines with nonlinear structures. Experimental results demonstrate the fast dynamic performance and excellent robust tracking of the proposed method.
\end{abstract}

Index Terms-Brushless Doubly-Fed Induction Machine, Cascade PI-SMC method, Matrix Converter.

\section{INTRODUCTION}

The brushless doubly-fed induction machine (BDFIM) [1-3] is a new type of ac induction machine which is developed from two cascaded asynchronous motors. Compared to the doubly-fed machine, the BDFIM not only inherits the advantages of doublyfed machine but also has a wider range of speed regulation. Moreover, the BDFIM has high reliability, good dynamic performance and does not need sliding rings and brushes. Therefore, the BDFIM has a broad application prospect in the field of wind power generation [4-5].

The matrix converter [6-7] can realize direct "AC-AC" conversion without using an intermediate DC link. Therefore, the power density ratio of the matrix converter is higher than that of dual pulse width modulation(PWM) converter. Besides, the switches of the matrix converter are bi-directional, so the matrix converter also has the characteristic of controllable input and four-quadrant operation of the motor. Since the matrix converter possesses the advantages of bi-directional power flow with the full four-quadrant operation, sinusoidal input and output currents, controllable input power factor, high power density, and no DC-link energy storage elements [8-9], using matrix converter as a frequency converter to drive BDFIM through appropriate control mode will be another promotion of wind power generation system.

To obtain high dynamic performance, many available studies regarding speed and torque control have been proposed for the BDFIM configuration [10-12]. In most of the literature, model predictive control (MPC) [10] and linear controllers such as 
proportional-integral (PI) are used [11-12]. In these methods, the speed controller typically covers the second-order dynamics of speed and current. However, the current inner loop of the BDFIM has a complex nonlinear structure and is easily interfered by various disturbances. Since Slide Mode Control (SMC) has the advantages of easy decoupling, disturbance rejection, insensitive to parameter variations, this method is often applied to control AC drives [13]. However, due to the inherent characteristics of SMC, it does not include solutions with constraints. It is an urgent problem to impose restrictions on SMC and use it in BDFIM [14-16]. This paper presents the application of cascade PI-second-order SMC for the BDFIM with the matrix converter. In this method, the out-loop PI controller tracks the reference rotor speed, and the inner-loop SMC method controls the reference control winding $(\mathrm{CW})$ current, which is the output value of the PI controller. The main advantages of this method are that the outer loop control provides constraints on the SMC through maximum current and speed limits and the super-twisting-based second-order SMC achieves fast and fixed convergence times.

This paper is organized as follows. In Section II, the mathematical model of the BDFIM and the working principle are described. Section III shows the sliding mode control of the brushless doubly-fed induction motor based on matrix converter, and then in section IV, the experimental verification of the PI-SMC of the BDFIM based on matrix converter is carried out, and the feasibility and correctness of the proposed method are proved. Section V concludes the research findings.

\section{MAthematical Model Of MAtrix CONVERTER AND BDFIM}

The basic structure of matrix converter and BDFIM is shown in Fig.1, where the input side of the matrix converter is an LC filter circuit for attenuate the switching frequency harmonics, and the output side is connected to the load. In this paper, the modulation method based on mathematical construction in [17] is applied. This method uses a mathematical construction method to directly obtain the switching duty cycle of the matrix converter, which can make the voltage utilization ratio of the matrix converter reach 0.866 .

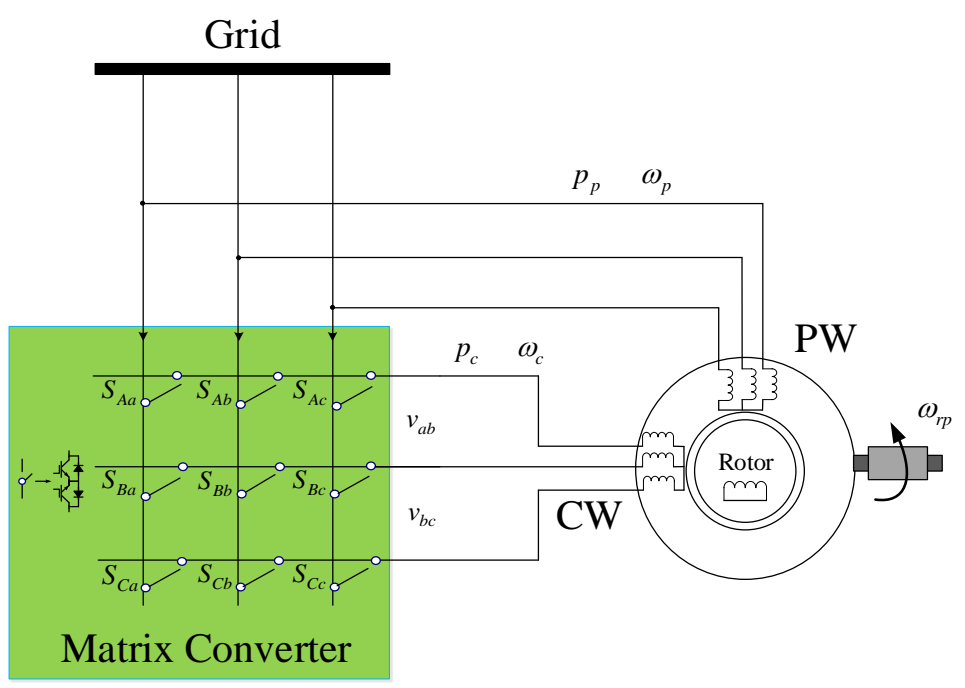

Fig. 1. The basic structure of the matrix converter and the BDFIM. 
The mathematical model of the BDFIM [18-19] is shown in equation (1):

$$
\left\{\begin{array}{l}
v_{p_{-} d q}=R_{p_{p_{-} d q}}+\frac{d \psi_{p_{-} d q}}{d t}+j \omega_{p} \psi_{p_{-} d q} \\
v_{c_{-} d q}=R_{c^{\prime}} i_{c_{-} d q}+\frac{d \psi_{c_{-} d q}}{d t}-j \omega_{c} \psi_{c_{-} d q} \\
0=R_{r} i_{r_{-} d q}+\frac{d}{d t} \psi_{r_{-} d q}+j \omega_{r p} \psi_{r_{-} d q} \\
\psi_{r_{-} d q}=L_{r} i_{r_{-} d q}+M_{p} i_{p_{-} d q}+M_{c} i_{c_{-} d q} \\
\psi_{p_{-} d q}=L_{p_{p_{-} d q}} i_{p^{\prime} r_{-} d q} \\
\psi_{c_{-} d q}=L_{c} i_{c_{-} d q}+M_{c} i_{r_{-} d q} \\
T_{e}=\frac{3}{2} p_{p} I_{m a g}\left(\psi_{p_{-} d q}\right)^{*} \bullet i_{p_{-} d q}+\frac{3}{2} p_{c} I_{m a g}\left(\psi_{c_{-} d q}\right)^{*} \bullet i_{c_{-} d q} \\
Q_{p w}=\frac{3 v_{p_{-} d q}}{2\left(L_{r} L_{p}-M_{p}^{2}\right)} M_{p} M_{c} i_{c_{-} d q}+\frac{3 L_{r} v_{p_{-} d q}^{2}}{2\left(L_{r} L_{p}-M_{p}^{2}\right) \omega_{p}}
\end{array}\right.
$$

where $v_{p_{-} d q}, v_{c_{-} d q}, i_{p_{-} d q}, i_{c_{-} d q}, i_{r_{-} d q}, \psi_{p_{-} d q}, \psi_{c_{-} d q}$ and $\psi_{r_{-} d q}$ are the power winding (PW) stator voltage vector, CW stator voltage vector, PW stator current vector, CW stator current vector, rotor current vector, PW stator flux vector, CW stator flux vector and rotor flux vector in the $D Q$ rotating coordinate system; $R_{p}, R_{c}, R_{r}, L_{P}, L_{c}$ and $L_{r}$ are the $\mathrm{PW}$ stator resistance, CW stator resistance, rotor resistance, $\mathrm{PW}$ stator inductance, $\mathrm{CW}$ stator inductance and rotor inductance; $M_{p}$ is the coupling inductance between the PW stator and rotor winding; $M_{c}$ is the coupling inductance between the $\mathrm{CW}$ stator and rotor winding; $T_{e}$ is the electromagnetic torque; $*$ is the conjugate symbol; $I_{m a g}$ is a symbol to obtain the imaginary part of vector. $\omega_{p}$ and $\omega_{c}$ are the angular frequencies of $\mathrm{PW}$ and $\mathrm{CW} ; p_{p}$ and $p_{c}$ are pole pairs of $\mathrm{PW}$ and $\mathrm{CW} ; \omega_{r p}$ is the angular speed of the rotor. $Q_{p w}$ is the reactive power. When the rotor resistance and the rotor flux are not considered, according to the equation (1), the voltage equation of the BDFIM can be obtained:

$$
\left\{\begin{array}{l}
\frac{d i_{c d}}{d t}=-\frac{\sigma_{1} R_{c}}{\sigma_{2}} i_{c d}+\frac{\sigma_{1}}{\sigma_{2}} v_{c d}-\omega_{c} i_{c q} \\
\frac{d i_{c q}}{d t}=-\frac{\sigma_{1} R_{c}}{\sigma_{2}} i_{c q}+\frac{\sigma_{1}}{\sigma_{2}} v_{c q}+\omega_{c} i_{c d}+D_{1}
\end{array}\right.
$$

where $\sigma_{1}=L_{p} L_{r}-M_{p}^{2}, \sigma_{2}=L_{c} L_{p} L_{r}-M_{c}^{2} L_{p}-M_{p}^{2} L_{c}$ and $D_{1}=\frac{M_{p} M_{c}}{\sigma_{2}} \psi_{p m}$.

\section{Sliding MOdel CONTROL OF BDFIM WITH MATRIX CONVERTER}

The sliding mode control diagram of BDFIM with matrix converter is shown in Fig. 2. The control method adopts a double closed-loop control structure. Among them, the outer loops adopt the conventional PI control strategy to realize the tracking of the reactive power of the power winding and the reference value of the rotor speed. The output of the outer loop controller is the 
reference of the stator current of the inner loop control side. To improve dynamic response of the stator current on the control side and the immunity of the system, a robust second-order sliding mode control is introduced as the current loop and obtain the desired reference voltage and duty cycle.

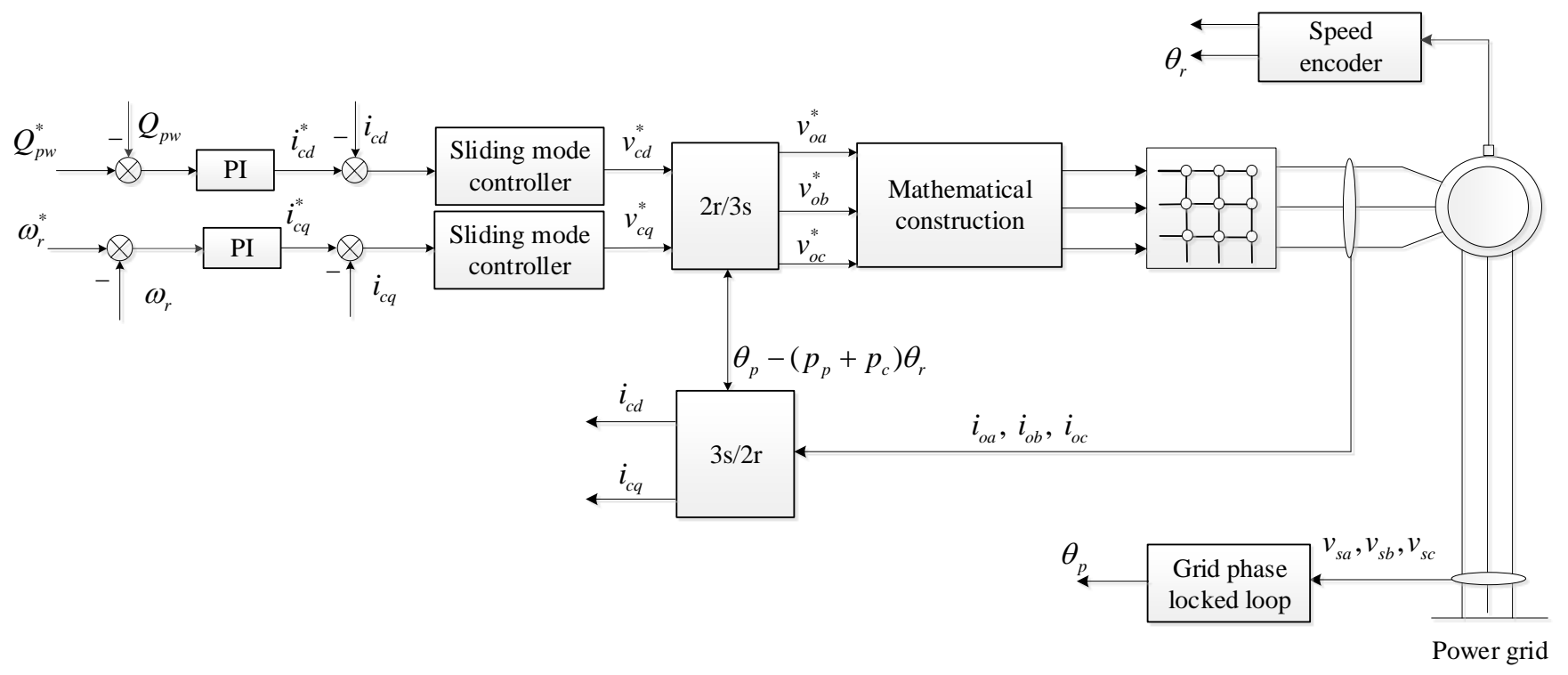

Fig. 2. Sliding mode control diagram of the brushless doubly-fed induction machine based on matrix converter

\section{A. Current loop design}

According to the nonlinear system shown in equation (2), in order to achieve zero steady-state error tracking of $i_{c d}^{*}$ and increase the degree of freedom in system bandwidth adjustment, the sliding mode surface is selected as follow:

$$
S_{s l}=X_{1}+\lambda_{1} X_{2}
$$

where $X_{1}=i_{c d}-i_{c d}^{*}, X_{2}=\int i_{c d}-i_{c d}^{*} d t, \lambda_{1}$ is the sliding mode coefficient, and the current loop bandwidth can be adjusted by adjusting $\lambda_{1}$. when it reaches the sliding surface, $S_{s l}=0, \dot{S}_{s l}=0$. So the steady-state error $i_{c d}$ can be expressed as:

$$
X_{1}(t)=X_{1}(0) e^{\lambda_{1} t}
$$

The control law of the sliding mode controller is selected as shown in equation (5):

$$
\left\{\begin{array}{l}
v_{c d}=v_{c d}^{e q}+v_{c d}^{s t} \\
v_{c d}^{e q}=\left(\frac{\sigma_{1} R_{c}}{\sigma_{2}} i_{c d}+\omega_{c} i_{c q}+\frac{d i_{c d}^{*}}{d t}-\lambda_{1} X_{1}\right) \frac{\sigma_{2}}{\sigma_{1}} \\
v_{c d}^{s t}=-c_{1}\left|S_{s l}\right|^{\frac{1}{2}} \operatorname{sign}(S)-c_{2} \int \operatorname{sign}\left(S_{s l}\right) d t
\end{array}\right.
$$

where $v_{c d}^{e q}$ is the equivalent control and $v_{c d}^{s t}$ is a super-twist control item, $c_{1}$ and $c_{2}$ are normal numbers, respectively. 
Considering that high frequency noise exists in the actual process, it is not easy to obtain the derivative of $i_{c d}^{*}$. In order to solve this problem, this paper uses a second-order sliding mode differentiator as shown in equation (6) to obtain the derivative of $i_{c d}^{*}$.

Suppose $i_{c d}^{*}$ contains Longberg measurement noise, and $\left(d i_{c d}^{*} / d t\right)<L$, then:

$$
\left\{\begin{array}{l}
\dot{z}_{0}=v_{0}, v_{0}=-\beta_{0} L^{1 / 3}\left|z_{0}-i_{c d}^{*}\right|^{2 / 3} \operatorname{sign}\left(z_{0}-i_{c d}^{*}\right)+z_{1} \\
\dot{z}_{1}=v_{1}, v_{1}=-\beta_{1} L^{1 / 2}\left|z_{0}-v_{0}\right|^{1 / 2} \operatorname{sign}\left(z_{0}-v_{0}\right)+z_{2} \\
\dot{z}_{2}=-\beta_{2} \operatorname{Lign}\left(z_{2}-v_{1}\right)
\end{array}\right.
$$

In the equation(6), the specific selection method of $\beta_{0}, \beta_{1}, \beta_{2}$ can refer to the literature[20]. In the case of $\beta_{0}, \beta_{1}, \beta_{2}, z_{0}, U_{0}$,

$Z_{1}$ is as shown in equation (7):

$$
\left\{\begin{array}{l}
z_{0}=i_{c d}^{*} \\
v_{0}=z_{1}=\frac{d i_{c d}^{*}}{d t}
\end{array}\right.
$$

\section{B. Speed loop design}

The outer loop of the speed adopts the conventional PI controller. According to the mathematical model of the BDFIM, it can be obtained as follow:

$$
J \frac{d \omega_{r}}{d t}=\frac{3 M_{p} M_{c}\left(p_{p}+p_{c}\right) \psi_{p m}}{2\left(L_{p} L_{r}-M_{p}^{2}\right)} i_{c q}-T_{L}-B_{g} \omega_{r}
$$

where $J$ and $B_{g}$ are the moments of inertia and friction coefficient; $T_{L}$ can be regarded as the disturbance item of the system, and the item $B_{g} \omega_{r}$ can usually be ignored. The factor before $i_{c q}$ is represented by $k_{\omega}$, then the equation (9) can be simplified as:

$$
\frac{d \omega_{r}}{d t}=k_{\omega} i_{c q}
$$

the system can be set as a first-order system only when the proportional term exists, but this will reduce the system's immunity. Therefore, in order to solve this problem, this paper introduces the active damping link in the conventional PI controller, as shown in equation (10):

$$
i_{c q}^{*}=k_{p}\left(\omega_{r}^{*}-\omega_{r}\right)+k_{i} \int_{0}^{t}\left(\omega_{r}^{*}-\omega_{r}\right) d t-k_{a} \omega
$$

The closed-loop transfer function of the system is shown in equation (11): 


$$
\Phi(s)=\frac{k_{\omega}\left(k_{p} s+k_{i}\right)}{s^{2}+k_{\omega}\left(k_{p}+k_{a}\right) s+k_{\omega} k_{i}}
$$

where $k_{p}=\omega_{a c} / k_{\omega}, k_{i}=\omega_{a c}^{2} / k_{\omega}, k_{a}=k_{p}$. Then the system can be set as the first-order link, and the control block diagram of the active loop with the active damping is shown in Fig. 3.

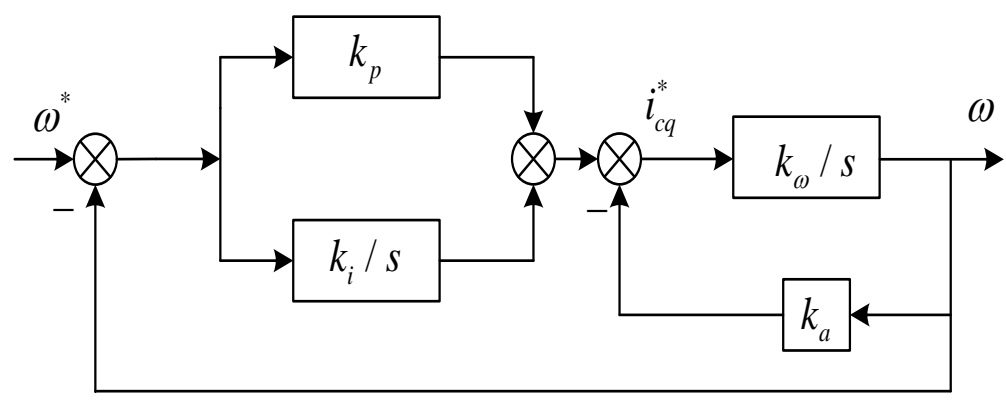

Fig. 3. Speed loop control block diagram with active damping

\section{Disturbance Analysis and Proof of Stability}

The current differential equation of the BDFIM with disturbance is shown in equation (12):

$$
\frac{d i_{c d}}{d t}=-\left(\frac{\sigma_{1} R_{c}}{\sigma_{2}}+\Delta_{1}\right) i_{c d}+\left(\frac{\sigma_{1}}{\sigma_{2}}+\Delta_{2}\right) v_{c d}-\omega_{c} i_{c q}+\Delta_{3}
$$

Among them, $\Delta_{1}$ and $\Delta_{2}$ are the errors caused by the parameter measurement, and $\Delta_{3}$ is the external interference. For ease of analysis, the error can be integrated into the form of equation (13):

$$
d=\Delta_{1} i_{c d}+\Delta_{2} v_{c d}+\Delta_{3}
$$

In practical engineering applications, matrix converters and BDFIM need to meet certain physical constraints in operation, the following assumptions can be made:

(1) The capacity of the matrix converter is limited, that is, the output of the matrix converter is limited;

(2) The disturbance of the brushless doubly-fed induction machine is bounded, and there is an upper limit for the parameter measurement error of the brushless doubly-fed induction machine. For example, as shown in the equation (14):

$$
\left\{\begin{array}{l}
R_{c}=\bar{R}_{c}+\Delta R_{c}, \quad L_{c}=\overline{L_{c}}+\Delta L_{c} \\
\Delta R_{c}<\varepsilon_{1}, \Delta L_{c}<\varepsilon_{2}
\end{array}\right.
$$

The superscripts $\bar{R}_{c}$ and $\bar{L}_{c}$ respectively represent the nominal value of the corresponding item, $\Delta R_{c}$ and $\Delta L_{c}$ respectively represent the error of the corresponding item, $\varepsilon_{1}$ and $\varepsilon_{2}$ respectively represent the upper limit of the corresponding item error. In summary, the error of the current loop is bounded, that is, where $d$ represents the upper limit of the known current loop error and 
$|d| \leq \varepsilon$. Proof of stability is given below.

When there is a disturbance in the system, the derivative $\dot{S}_{s l}$ of the sliding surface can be rewritten as:

$$
\dot{S}_{s l}=\dot{X}_{1}+\lambda_{1} X_{1}+d
$$

Combining equations (5) and (15), the closed-loop equation of the system is:

$$
\left\{\begin{array}{c}
\dot{S}_{s l}=-c_{1}\left|S_{s l}\right|^{\frac{1}{2}} \operatorname{sign}\left(S_{s l}\right)+v+d \\
\dot{v}=-c_{2} \operatorname{sign}(S)
\end{array}\right.
$$

In order to prove the stability of the system, the Lyapufu function is selected as:

$$
V=2 c_{2}\left|S_{s l}\right|+\frac{1}{2} v^{2}+\frac{1}{2}\left(c_{1}\left|S_{s l}\right|^{1 / 2} \operatorname{sign}\left(S_{s l}\right)-v\right)^{2}=\zeta^{T} P_{s l} \zeta
$$

Where $\zeta^{T}$ and $P$ are respectively expressed as

$$
\begin{aligned}
& \zeta^{T}=\left[\left|S_{s l}\right|^{1 / 2} \operatorname{sign}\left(S_{s l}\right) v\right] \\
& P_{s l}=\frac{1}{2}\left[\begin{array}{cc}
4 c_{2}+c_{1}^{2} & -c_{1} \\
-c_{1} & 2
\end{array}\right]
\end{aligned}
$$

The equation (17) is derived:

$$
\dot{V}=-\frac{1}{\left|S_{s l}\right|^{1 / 2}} \zeta^{T} Q \zeta+\frac{d}{\left|S_{s l}\right|^{1 / 2}} q^{T} \zeta
$$

Where $Q$ and $q^{T}$ are respectively expressed as:

$$
Q=\frac{c_{1}}{2}\left[\begin{array}{cc}
2 c_{1}+c_{1}^{2} & -c_{1} \\
-c_{1} & 1
\end{array}\right], \quad q^{T}=\left[\left(2 c_{2}+\frac{c_{1}^{2}}{2}\right)-\frac{c_{1}}{2}\right]
$$

Since the disturbance of the current loop is bounded, it can be obtained by combining the literature [21-22]:

$$
\dot{V} \leq-\frac{1}{|S|^{(1 / 2)}} \zeta^{T} \tilde{Q} \zeta
$$

Where

$$
Q=\frac{c_{1}}{2}\left[\begin{array}{cc}
2 c_{2}+c_{1}^{2}-\left(\frac{4 c_{2}}{c_{1}}+c_{1}\right) \varepsilon & -\left(c_{1}+2 \varepsilon\right) \\
-\left(c_{1}+2 \varepsilon\right) & 1
\end{array}\right]
$$


Generally speaking, when $V$ is positive and $\dot{V}$ is negative, the system satisfies the asymptotic stability condition, at this time $Q>0$. Therefore, by reasonably setting the values of $c_{1}$ and $c_{2}$, the system can still be stabilized under bounded interference.

The choice of $c_{1}$ and $c_{2}$ is shown in equation (24):

$$
\left\{\begin{array}{l}
c_{1}>2 \varepsilon \\
c_{2}>c_{1} \frac{5 c_{1} \varepsilon+4 \varepsilon^{2}}{2\left(c_{1}-2 \varepsilon\right)}
\end{array}\right.
$$

\section{EXPERIMENTAL VERIFICATION}

\section{A. Experimental Setup}

In order to verify the correctness of the cascade PI-SMC method for BDFIM with MC, the experimental prototype is set up. Fig.4 (a) shows the prototype of the matrix converter used in the experiment. The prototype consists of four parts: control system, clamp system, drive system and IGBT module. The control system is DSP (TMS320F28335) and Field-Programmable Gate Array (FPGA, EP2C8T144C8N) are the main body to realize the control of the speed loop and current loop of the BDFIM and obtain the final duty ratio. The function of the drive system is to convert the acquired duty cycle into high and low levels to drive the IGBT of the matrix converter. The function of the clamp system is to prevent damage to the matrix converter caused by failures such as commutation failure. Fig. 4 (b) shows the physical diagram of the BDFIM used in the experiment. The relevant parameters of the matrix converter and the BDFIM are shown in Table I.

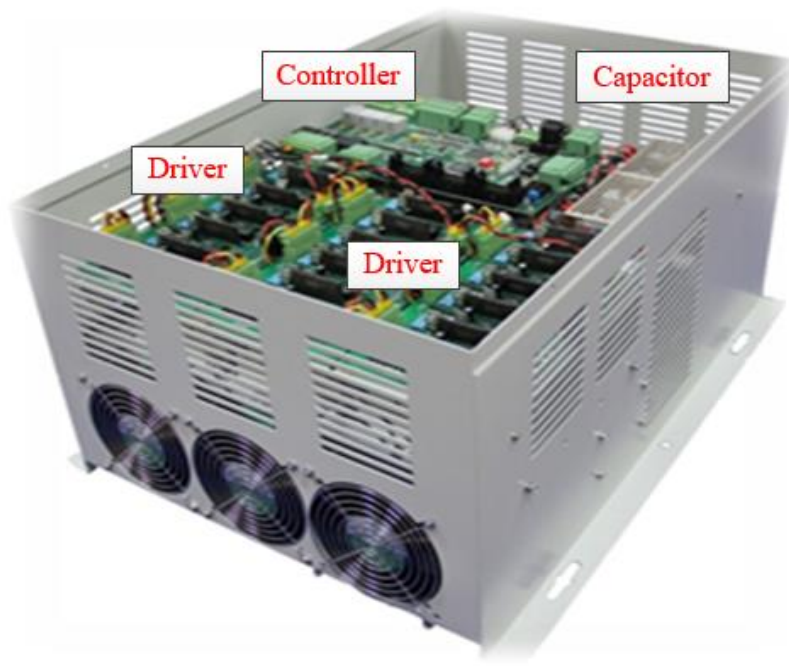

(a)

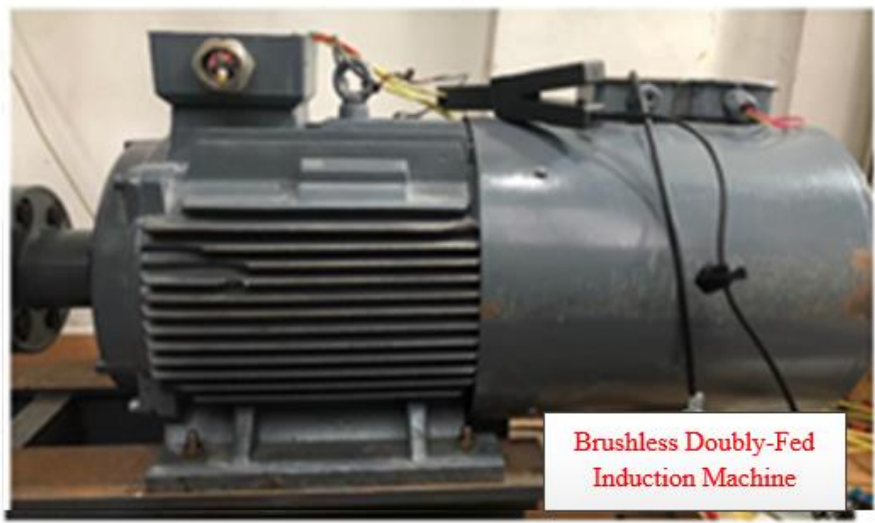

(b)

Fig. 4. Experimental device diagram (a). Matrix converter prototype; (b). Brushless doubly-fed induction machine. 
TABLE I

Experimental parameters

\begin{tabular}{cc}
\hline Parameter & Value \\
\hline Grid phase voltage $(\mathrm{V})$ & 85 \\
Filter capacitor $(\mu \mathrm{F})$ & 66 \\
Filter inductor $(\mathrm{mH})$ & 0.6 \\
Passive damping resistance $(\Omega)$ & 9 \\
the number pole pairs of the $\mathrm{PW}$ & 1 \\
the number of pole pairs of the $\mathrm{CW}$ & 3 \\
$R_{p}(\Omega)$ & 1.6 \\
$R_{c}(\Omega)$ & 1.83855 \\
$R_{r}(\Omega)$ & 0.8306 \\
$L_{p}+L_{c}(\mathrm{mH})$ & 82.495 \\
$M_{p}(\mathrm{mH})$ & 24.28 \\
$M_{c}(\mathrm{mH})$ & 2.54 \\
\hline
\end{tabular}

\section{B. Analysis of Sliding Mode Control Characteristics}

In order to verify the performance of sliding mode control, the $\sigma_{2} / \sigma_{1}$ of the mathematical model of the BDFIM is reduced by $1 / 5$ in the design of the sliding mode controller, and compared with the vector control method based on matrix converter. The outer loop of vector control is the same as the outer loop of sliding mode control, and the motor parameters used in vector control are unchanged.

\section{1) Astringency}

Fig. 5shows the waveforms of the stator voltage, stator current and grid voltage on the control winding side of the BDFIM at a given speed of 400r/min. In the case of constant speed, Fig.5 (a) shows the output waveform of matrix converter under the proposed PI-SMC method, Fig.5 (b) shows the output waveform of matrix converter under conventional vector control.

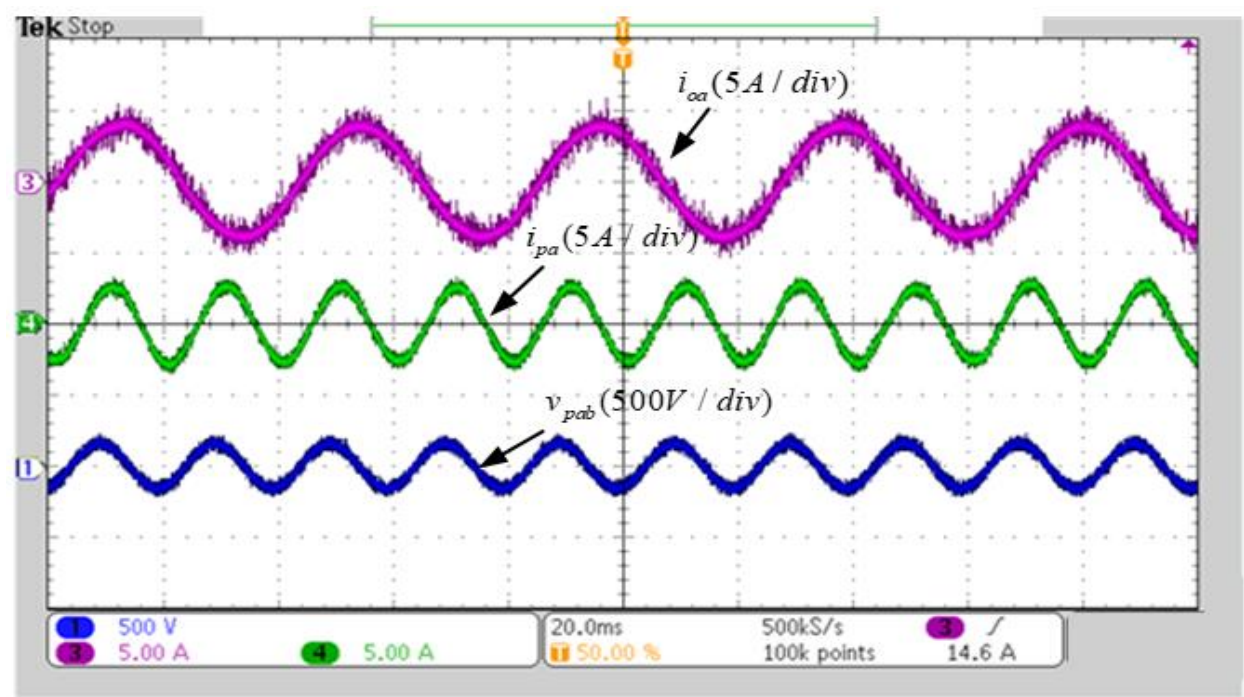

(a) 


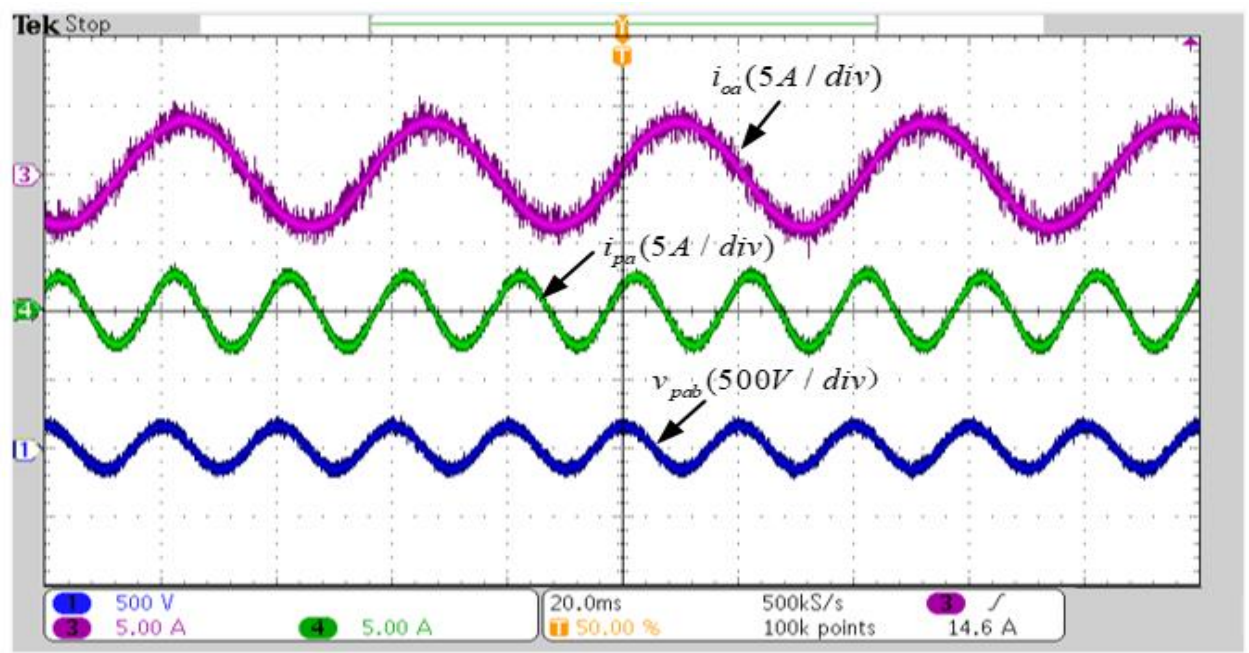

(b)

Fig. 5. Output waveform under constant speed (a) Output waveform of matrix converter under the proposed PI-SMC method; (b) Output waveform of matrix converter under conventional vector control

According to Fig. 5, the sliding mode control is also used when the error is bounded. The matrix converter output current can be guaranteed to be sinusoidal, achieving the same control effects as conventional vector control.

2) Steady state performance
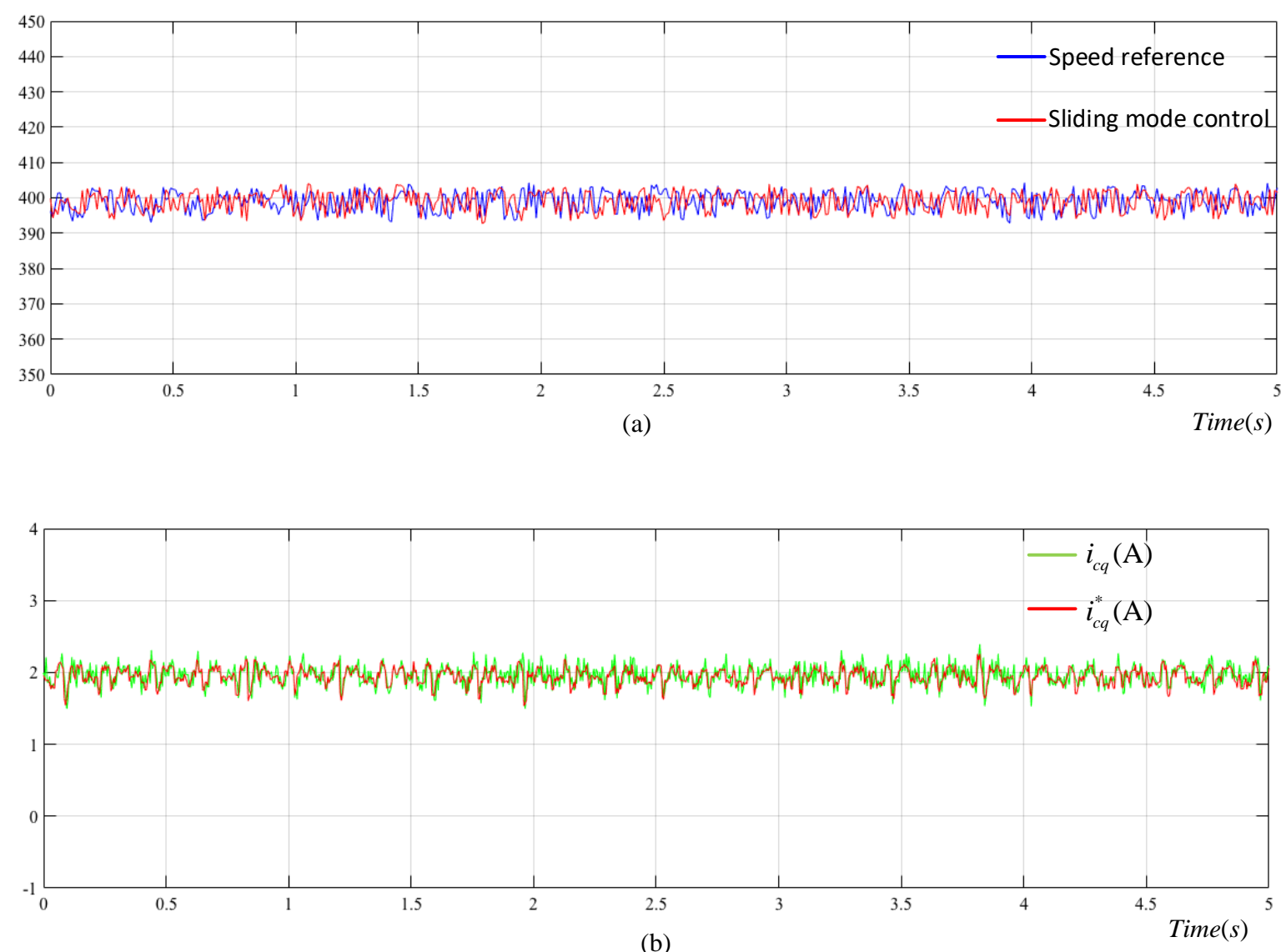
Fig. 6. (a) Speed reference value 400r/min sliding mode control and vector control speed comparison chart; (b) Contrast figure of stator current waveforms produced by sliding mode control

Fig.6 (a) shows the comparison of the speed of the proposed sliding mode control with the conventional vector control when the given speed is 400r/min. As can be seen, in the case of constant speed reference, the proposed sliding mode control can still track the reference value of the upper speed well, and the speed control effect is equivalent to the conventional vector control. Fig. 6 (b) shows the waveforms of $i_{c q}$ and $i_{c q}^{*}$ of the BDFIM with the reference speed 400r/min under the control of the proposed PI-SMC method. As shown in Fig.6 (b), $i_{c d}$ and $i_{c q}$ of the BDFIM tracked the set value very well. Fig.6 shows that the proposed PI-SMC method has a good tracking effect and has the same steady-state performance than the conventional vector control.

3) Dynamic performance

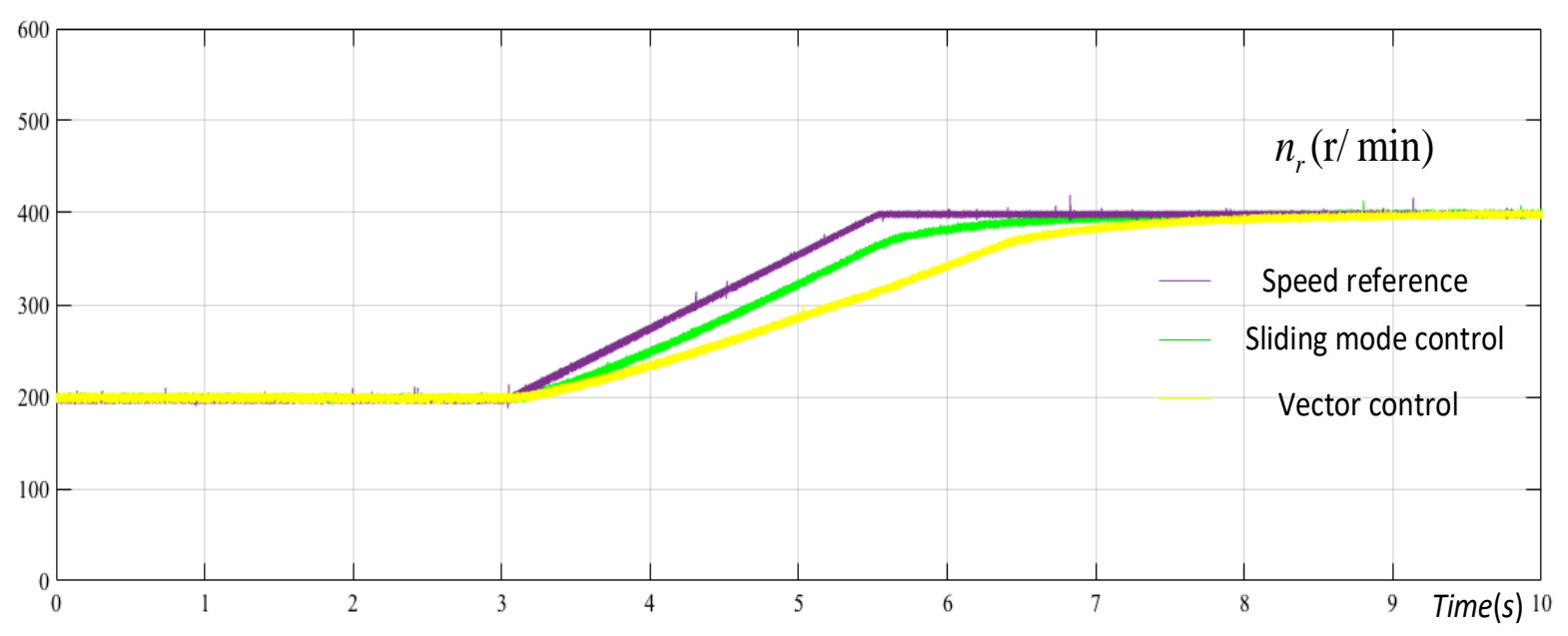

Fig. 7. Comparison of the proposed PI-SMC method and vector control

Fig.7 shows the dynamic performance comparison between the proposed sliding mode control and the conventional vector control when the speed is given by the ramp and the speed is changed from 200r/min to 400r/min. As shown in Fig.7, when the speed changes suddenly, sliding mode control can track the given speed faster than conventional vector control. it shows that the sliding mode control has better dynamic performance.

Therefore, from the above experimental results, it can be seen that the sliding mode control system of the BDFIM based on matrix converter proposed has strong anti-interference ability. Based on meeting the requirements of tracking effect and steadystate characteristics, it has better dynamic characteristics than conventional vector control methods.

\section{CONCLUSION}

In this paper, the cascade PI-SMC method for BDFIM with matrix converter is proposed. The outer loop adopts the conventional PI controller to follow the reference value of the rotational speed and reactive power. The inner loop uses a second-order sliding 
mode controller to control the CW current of the brushless doubly-fed motor and obtain the desired output voltage. Finally, the desired output voltage is modulated by a mathematical construction modulation method to obtain the switching duty cycle of the matrix converter. The experimental results verify the correctness and effectiveness of the proposed method.

\section{REFERENCES}

[1] L. J. Hunt, "A new type of induction motor," Electrical Engineers, Journal of the Institution of, vol. 39, no. 186 , pp. 648-667, September 1907.

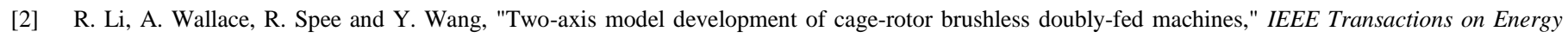
Conversion, vol. 6, no. 3, pp. 453-460, Sept. 1991.

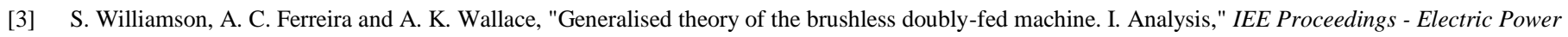
Applications, vol. 144, no. 2, pp. 111-122, Mar 1997.

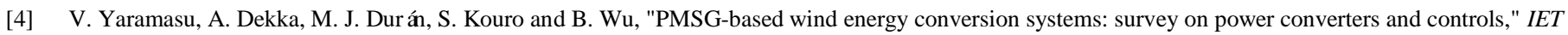
Electric Power Applications, vol. 11, no. 6, pp. 956-968, 72017.

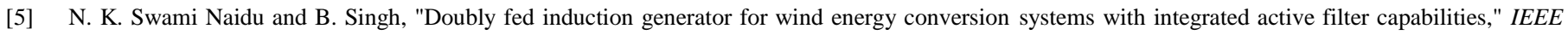
Transactions on Industrial Informatics, vol. 11, no. 4, pp. 923-933, Aug. 2015.

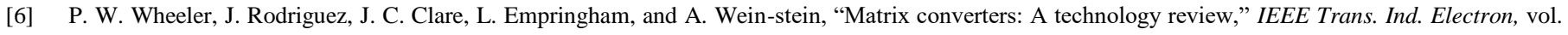
49, no. 2, pp. 276-288, Apr. 2002.

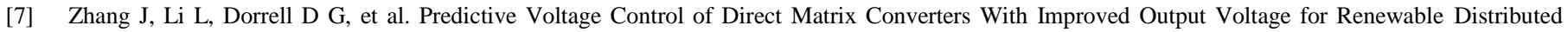
Generation[J]. IEEE Journal of Emerging and Selected Topics in Power Electronics, 2018, 7(1): 296-308.

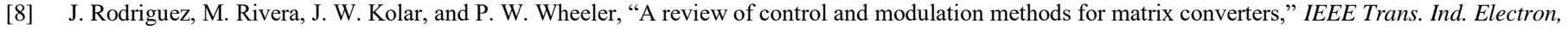
vol. 59, no. 1, pp. 58-70, 2012.

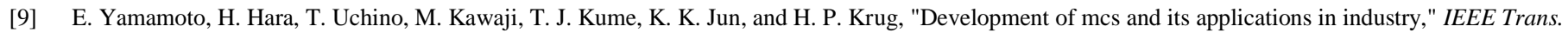
Ind. Electron, vol. 5, pp. 4-12, 2011.

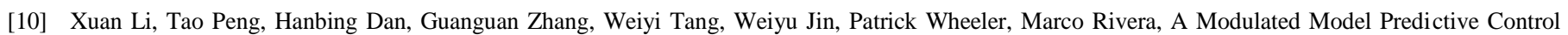
Scheme for the Brushless Doubly-Fed Induction Machine, IEEE Journal of Emerging and Selected Topics in Power Electronics, $2018,6(4)$ : 1681-1691.

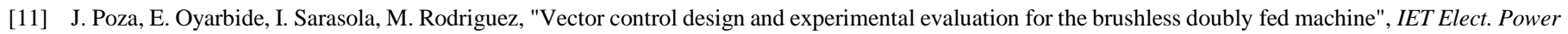
Appl, vol. 3, no. 4, pp. 247-256, Jul. 2009.

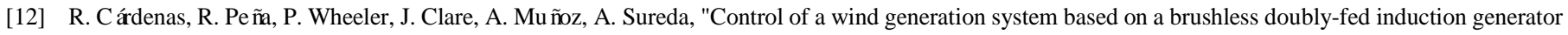
fed by a matrix converter", Electric Power Syst. Res, vol. 103, pp. 49-60, Oct. 2013.

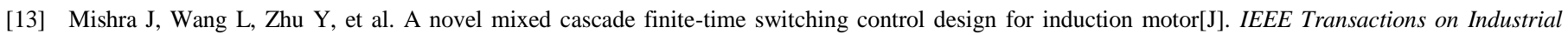
Electronics, 2018, 66(2): 1172-1181.

[14] Y. Shtessel, C. Edwards, L. Fridman, and A. Levant, Sliding Mode Control and Observation. New York, NY, USA: Birkhauser, 2014.

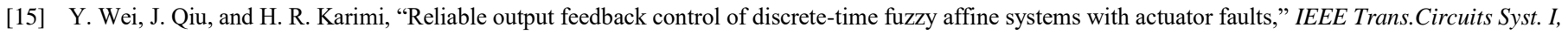
Reg. Papers, vol. 64, no. 1, pp. 170-181, Jan. 2017.

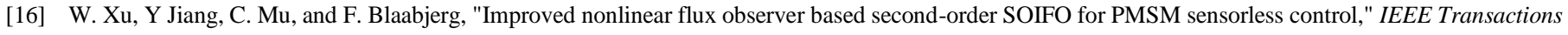
on Power Electronics, vol. 34, no.1, pp.565-579, Jan. 2019.

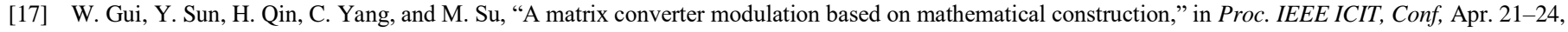
2008, pp. 1-5. 
[18] Sajjad Tohidi, "Analysis and simplified modelling of brushless doubly-fed induction machine in synchronous mode of operation," IET Electr. Power Appl., 2016, Vol. 10, Iss. 2, pp. 110-116.

[19] Xuan Li, Tao Peng, Hanbing Dan, Guanguan Zhang, Weiyi Tang, Weiyu Jin, Patrick Wheeler, Marco Rivera, "A Modulated Model Predictive Control Scheme for the Brushless Doubly-Fed Induction Machine," 2017 IEEE Energy Conversion Congress and Exposition (ECCE), Cincinnati, OH, USA, 2017, pp.1338-1342, Oct. 2017.

[20] Levant A. Higher-order sliding modes, differentiation and output-feedback control[J]. International journal of Control, 2003, 76(9-10): 924-941.

[21] Moreno J A, Osorio M. Strict Lyapunov functions for the super-twisting algorithm[J]. IEEE transactions on automatic control, 2012, 57(4): 1035-1040.

[22] W. Xu, K. Yu, Y. Liu* and J. Gao, "Improved coordinated control of standalone brushless doubly-fed induction generator supplying nonlinear loads," IEEE Transactions on Industrial Electronics, pp, Dec. 2018. 